\title{
HYDROTHERMAL SYNTHESIS of ZnO FILMS and CHARACTERIZATION
}

\section{Olcay GENÇYILMAZ*}

Department of Physics, Faculty of Sciences, Çankırı Karatekin University, Çankırı, Turkey

\begin{abstract}
In this study, $\mathrm{ZnO}$ films were produced by hydrothermal synthesis onto glass substrates. The structural properties of $\mathrm{ZnO}$ films were examined using X-ray diffraction (XRD) techniques. According to XRD results, the high quality polycrystalline $\mathrm{ZnO}$ films were achieved at low temperature. Spectroscopic ellipsometry (SE) technique and Cauchy-Urbach model were used to the important optic constants of films as the thickness $(d)$, refractive index $(n)$ and extinction coefficient $(k)$. The transmittance, absorbance and reflectance spectra of films were obtained by Uv-vis spectrophotometer and optical properties were analyzed using these spectra. Also, the surface properties, roughness and electrical resistivity values were investigated by atomic force microscopy (AFM), field emission scanning electron microscopy (FESEM) and four-probe technique, respectively. Finally, the characterization results of $\mathrm{ZnO}$ films showed that, hydrothermal synthesis allowed production of $\mathrm{ZnO}$ films which higher quality than other techniques at low temperature.
\end{abstract}

Keywords: Hydrothermal synthesis, ZnO films, XRD, Optic constants, Surface properties

\section{INTRODUCTION}

Recently, $\mathrm{ZnO}$ semiconductors have been comprehensively studied because of their potential applications in optoelectronics, microelectronics, catalysis, and piezoelectricity. For these application areas, $\mathrm{ZnO}$ films are one of the most important materials. $\mathrm{ZnO}$ films have wide direct band gap ( $\sim 3.37$ $\mathrm{eV})$, high binding exciton energy $(60 \mathrm{meV})$ and unique physical properties such as optical, electrical, structural, mechanical and piezoelectric properties [1].

$\mathrm{ZnO}$ films have been produced various chemical and physical techniques as sol-gel [2], spray pyrolysis [3], hydrothermal synthesis [4], chemical bath deposition [5], pulsed laser deposition [6], thermal evaporation [7]. The best part of these techniques has some advantages and disadvantages. Especially, although chemical techniques have practically and easy to growth control, a lot of these techniques have not the controlling of homogeneity and structure. Also, these techniques mostly allow to the production of films at high temperature. So, the surface morphology and structure of films which are produced chemical techniques have not control and this case induces restriction of application areas. Among these techniques, hydrothermal synthesis is an aqueous solution-based technique such as chemical bath deposition for deposition of various films and it is simple, economical [8-12]. Recently, this technique has been attracted attention the production of films at significantly low temperature $[8,13]$. Because this technique has some advantages such as low temperature, inexpensive equipment, easy to prepare and nontoxic. Also, hydrothermal synthesis allows for large-scale manufacturing materials with various morphology and structure. These properties are very important for $\mathrm{ZnO}$ films production in the different application areas of usage. There are many studies on the nanostructure $\mathrm{ZnO}$ production by hydrothermal synthesis. But, to our knowledge, there is too little study about production of $\mathrm{ZnO}$ films at low substrate temperatures by hydrothermal synthesis. Although there are many studies on the physical properties of $\mathrm{ZnO}$ films, spectroscopic ellipsometry (SE) studies of $\mathrm{ZnO}$ films, which are produced at low deposition temperature, have not been reported in detail. 
For these reason, in this study, we focused on the production of $\mathrm{ZnO}$ films at low substrate temperature. In this study, the production of $\mathrm{ZnO}$ films on a glass substrate using hydrothermal synthesis at low substrate temperature. Besides, we have been reported on the structural, optical [thickness $(d)$, refractive index $(n)$ and extinction coefficient $(k)$ ], surface, and electrical properties of $\mathrm{ZnO}$ films which have been investigated by spectroscopic ellipsometry (SE) and suitable analysis techniques.

\section{EXPERIMENTAL}

\subsection{Film Formation}

$\mathrm{ZnO}$ films were produced using hydrothermal synthesis onto a glass substrate. $0.1 \mathrm{M}(30 \mathrm{ml})$ of zinc nitrate hexahydrate $\left[\mathrm{Zn}\left(\mathrm{NO}_{3}\right)_{2} \cdot \mathrm{H}_{2} \mathrm{O}\right]$ and $0.05 \mathrm{M}(30 \mathrm{ml})$ sodium hydroxide $[\mathrm{NaOH}]$ aqueous solutions were solved with deionized water and these solutions were stirred with magnetic stirring at $50{ }^{\circ} \mathrm{C}$ during 1 hour. Afterwards, $\mathrm{NaOH}$ solution was vigilantly added into the $\left[\mathrm{Zn}\left(\mathrm{NO}_{3}\right)_{2} \cdot \mathrm{H}_{2} \mathrm{O}\right]$ solution until $\mathrm{pH}$ value reach 10 and this solution was stirred at $120^{\circ} \mathrm{C}$ during 3 hours. The glass substrate was placed into the solution, which the reaction was completed, and this solution was cooled to room temperature normally. The synthesized $\mathrm{ZnO}$ sample was washed deionized water, ethanol and acetone, respectively and final sample was dried in an oven at $80{ }^{\circ} \mathrm{C}$ during 1 hours.

\subsection{Film Characterization}

The crystallographic studies were performed using Bruker D8 Advance X-ray diffractometer using $\mathrm{CuK}_{\alpha}$ wavelength $(k=1.5406 \AA)$ and scanning in $2 \theta$ range from $20^{\circ}$ to $70^{\circ}$. Optical transmittance, absorbance and reflectance of films were carried out on UV-2550 UV-Vis spectrophotometer. The band gap energy values for these films were calculated by optic method. Ellipsometric measurements [thickness $(d)$, refractive index $(n)$ and extinction coefficient $(k)$ ] of films were made on PHE102 spectroscopic ellipsometer. Electrical resistivity values of films were determined using Keithley 2601 A System Source meter Lucas Labs four-point probe setup. The surface morphology were investigated using ZEISS Ultraplus model field emission scanning electron microscopy (FESEM) and Park System $\mathrm{XE}$ atomic force microscopy (AFM) where topography images were taken in noncontact mode, $\sim 300$ $\mathrm{kHz}$ frequency and $0.90 \mathrm{~Hz}$ scan rate in air at room temperature. A silicon cantilever which has a spring constant of $40 \mathrm{~N} / \mathrm{m}$ was used. Also, the roughness values of films (root mean square $\left(\mathrm{rms}, R_{q}\right)$, average $\left(R_{a}\right)$ and peak valley $\left.\left(R_{p v}\right)\right)$ were obtained using XEI version 1.7.1 software in AFM.

\section{RESULTS AND DISCUSSION}

XRD pattern (Fig. 1) of $\mathrm{ZnO}$ film produced by hydrothermal synthesized on glass substrate. We observed that $\mathrm{ZnO}$ film have very sharper diffraction peak for (002) orientations and good crystalline structure according to other chemical techniques [14-16]. The film has a polycrystalline hexagonal wurtzite crystal structure and the best crystallization level. The $\mathrm{ZnO}$ film has (002) as the preferred orientation. Other orientations similar (100), (101), (102), (110), (103) are also seen relatively lower intensities. There are no characteristic peaks of other impurities.

Also, we calculated some the structural parameters to obtain information about the structural properties in detail using the formulas below $[17,18]$.

$$
\begin{aligned}
\mathrm{TC}(\mathrm{hkl}) & =\frac{\mathrm{I}(\mathrm{hkl}) / \mathrm{I}_{0}(\mathrm{hkl})}{\mathrm{N}^{-1} \sum_{\mathrm{n}} \mathrm{I}(\mathrm{hkl}) / \mathrm{I}_{0}(\mathrm{hkl})} \\
\mathrm{D} & =\frac{0.9 \lambda}{\beta \cos \theta}
\end{aligned}
$$




$$
\begin{aligned}
& \delta=\frac{1}{\mathrm{D}^{2}} \\
& <e>=\frac{d}{d-d_{0}}
\end{aligned}
$$

where $I_{0}$ represents the standard intensity (ASTM), $I$ the observed intensity of $(h k l)$ plane, $\mathrm{n}$ the reflection number, $\mathrm{D}$ the grain size size of the films, $(\lambda=1.5405 \AA)$ the wavelength of $\mathrm{X}$-rays used, $\beta$ the broadening of diffraction line measured at half its maximum intensity in radians, $\theta$ the angle of diffraction, $d$ the interplanar spacing, and $d_{0}$ the interplanar spacing without deformation. All calculated values and structural parameters are given in Table I. As seen from Table I and XRD pattern of ZnO film produced in $\mathrm{NaOH}$ solution present the highest preferential orientation of the $\mathrm{ZnO}$ film along the caxis at (002) plane.

Table 1. Structural parameters of the $\mathrm{ZnO}$ film

\begin{tabular}{|c|c|c|c|c|c|c|c|c|}
\hline Film & $2 \theta\left(^{\circ}\right)$ & $\mathrm{d}(\AA)$ & $(\mathrm{hkl})$ & $\begin{array}{c}\text { Crystal } \\
\text { System }\end{array}$ & $\mathrm{TC}(\mathrm{hkl})$ & $\delta\left(\right.$ line $\left./ \mathrm{nm}^{2}\right)$ & $\mathrm{D}(\mathrm{nm})$ & $<\mathrm{e}>$ \\
\hline $\mathrm{ZnO}$ & 34.488 & 2.5844 & $(002)$ & $\begin{array}{c}\mathrm{ZnO} \\
\text { Hexagonal }\end{array}$ & 4.96 & $1.02 \times 10^{-3}$ & 28.3 & $2.07 \times 10^{-2}$ \\
\hline
\end{tabular}

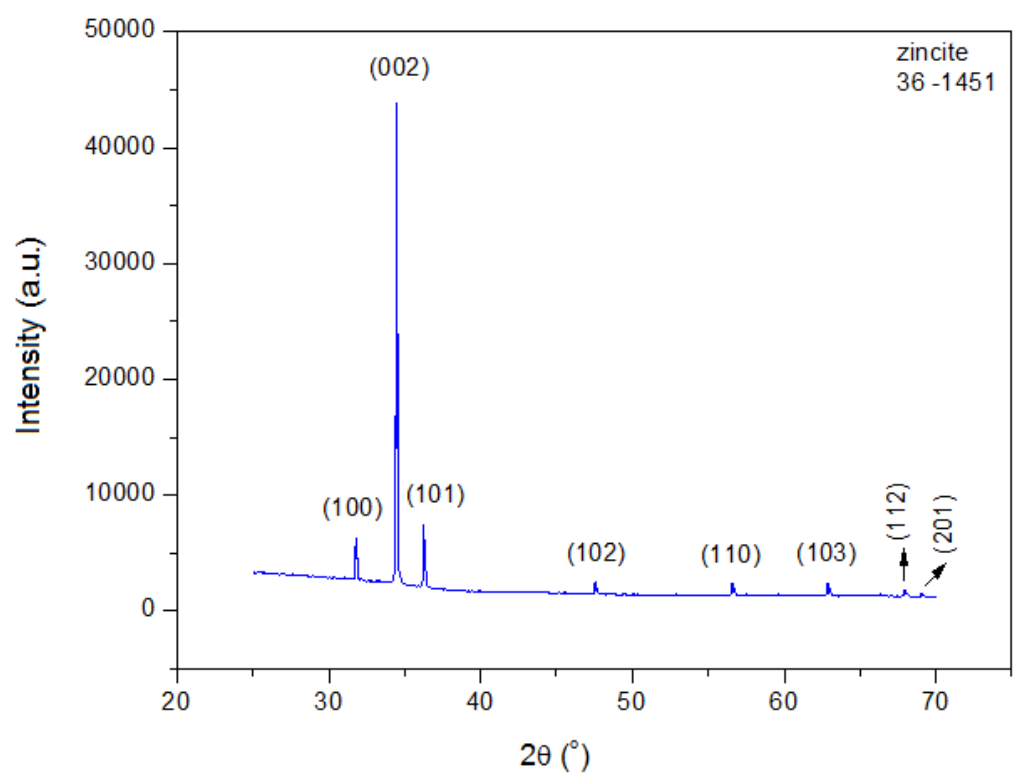

Figure 1. XRD pattern of $\mathrm{ZnO}$ film

The several techniques are used to the determination of optical constants. As an optical technique, SE is non-destructive, very sensitive and contactless to the optical parameters, especially semiconductors. This technique depends on the analysis of the change of the polarization of light upon the reflection from the film surface. This change can be represented by the ratio of reflection coefficient;

$$
\frac{R_{p}}{R_{S}}=\operatorname{tg} \psi e^{i \Delta}
$$

where $R_{p}$ and $R_{s}$ are ratios of the reflected wave amplitude to the indecent wave amplitude for the $\mathrm{p}$ and s-component, respectively. The shape of the ellipse is depicted by $\Delta$, which reflects the change in phase difference between p-polarized component $\delta_{l}$ and the s-polarized component $\delta_{2}$ of the incident and reflected wave. $\psi$ depicts the orientation of the ellipse and $\operatorname{tg}(\psi)$ is the absolute value of $R_{p} / R_{s}[19]$. 
SE measurements have been done in a wavelength range of $300-900 \mathrm{~nm}$ at the three different indicent angles and cos (delta) spectra have been recorded at each wavelength and angle of incidence. CauchyUrbach dispersion model, which is suitable for semiconductors, was used to fit the experimental data. In the Cauchy-Urbach dispersion model, the refractive index $\mathrm{n}(\lambda)$ and the extinction coefficient $\mathrm{k}(\lambda)$ as a function of the wavelength are given by,

$$
\begin{aligned}
& n(\lambda)=A_{n}+\frac{B_{n}}{\lambda^{2}}+\frac{C_{n}}{\lambda^{4}} \\
& k(\lambda)=A_{k} \cdot e^{B_{k}\left(E-E_{b}\right)}
\end{aligned}
$$

where $A_{n}, B_{n}, C_{n}, A_{k}$, and $B_{k}$ are model parameters [20]. For the samples having depolarization effect, the incident angle is an important factor. Three different incident angles $\left(50^{\circ}, 60^{\circ}\right.$ and $\left.70^{\circ}\right)$ were tried to take the measurements. The best angle was determined to be $60^{\circ}$ using experimental w spectra. Then, the parameters $\left(A_{n}, B_{n}, C_{n}, A_{k}, B_{k}\right)$ related to the Cauchy-Urbach model have been determined. Cauchy-Urbach model determined an approximate film thickness and refractive index. It is desirable to find a region of the measured spectral range where the film is nearly transparent. This allows simpler models with fewer parameters to be used in the fitting the data. The measured values were best fitted using Cauchy-Urbach dispersion model. Figure 2 shows cos (delta) fit to the experimental data over the spectral range 300 to $900 \mathrm{~nm}$. A good fit is found between experimental and model data. However, there are some small deviations on cos (delta) values between model and experimental data. We think that, these deviations are probably due to the depolarizing effect of roughness, backside reflection of glass substrates, grain boundaries, and morphologies of the films which affect the experimental data. Also, thicknesses and model parameters are given in Table 2.

Refractive index values are an important optic parameter for the alternative applications and the TCO materials. Also, the chemical production technique of $\mathrm{ZnO}$ film has an important effect on refractive index and extinction coefficient. Figure 3 shows the $n$ and $k$ spectra of $\mathrm{ZnO}$ films. It is clear that $\mathrm{ZnO}$ film have nearly the same behavior for refractive index and extinction coefficient spectra. The $\mathrm{ZnO}$ films had normal dispersion for the entire range of wavelength studied. The refractive index value of $\mathrm{ZnO}$ film is determined $\sim 2.1$ in visible region and this value conform to in literature. The refractive index and extinction coefficient values are nearly remain constant in long wavelength.



Figure 2. Spectroscopic ellipsometry (SE) spectra of $\mathrm{ZnO}$ film 
Table 2. Thicknesses and SE model parameters

\begin{tabular}{|c|c|c|c|c|c|c|c|}
\hline Film & $\mathrm{d}(\mathrm{nm})$ & $\mathrm{A}_{\mathrm{n}}$ & $\mathrm{B}_{\mathrm{n}} \times 10^{-2}(\mathrm{~nm})^{2}$ & $\mathrm{C}_{\mathrm{n}} \times 10^{-2}(\mathrm{~nm})^{4}$ & $\mathrm{~A}_{\mathrm{k}}$ & $\mathrm{B}_{\mathrm{k}}(\mathrm{eV})^{-1}$ & MSE \\
\hline $\mathrm{ZnO}$ & 96 & 2.35 & 3.36 & 1.20 & 1.16 & 2.72 & 0.22 \\
\hline
\end{tabular}

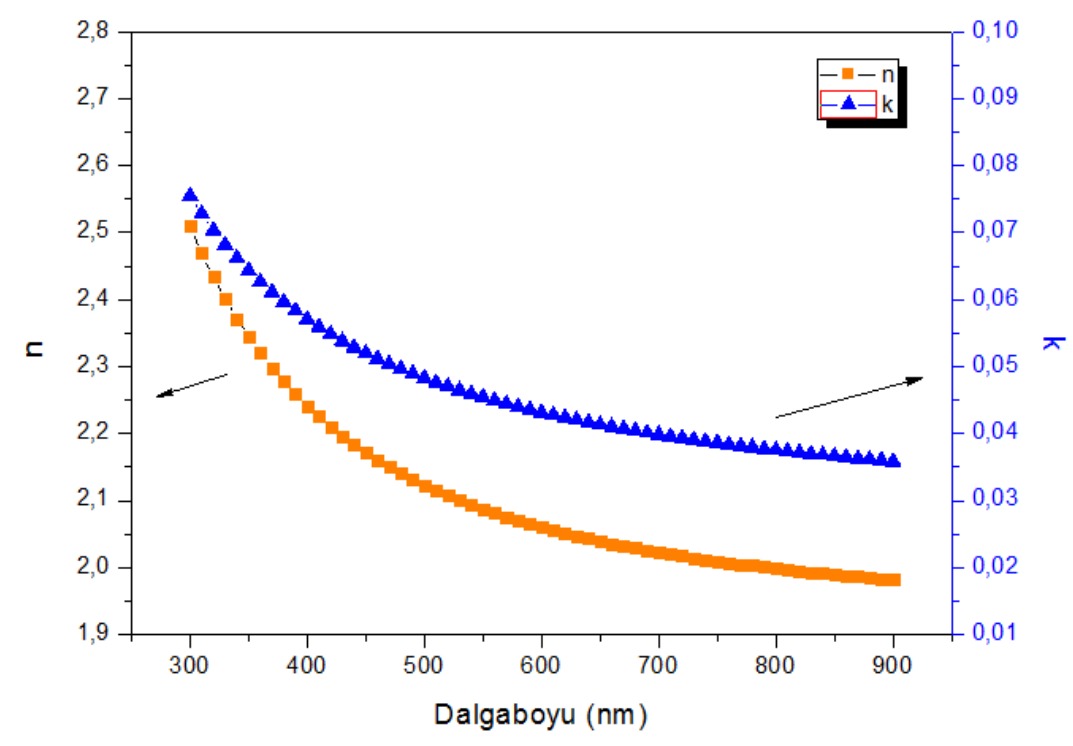

Figure 3. Refractive index $(n)$ and extinction coefficient $(k)$ spectra of $\mathrm{ZnO}$ film

The optical properties were examined by UV-Visible (UV-Vis) spectrophotometer and the optical characterization $\mathrm{ZnO}$ films were performed by transmittance $(T)$, absorbance $(A)$ and reflectance $(R)$ spectra from 300 to $900 \mathrm{~nm}$. The all spectra of films are presented in Figure4. From Figure 4 (a) it is clear that the optical transmittance value of $\mathrm{ZnO}$ film is around $80 \%$ in the visible region (400-700 $\mathrm{nm}$ ). This value may be low for some application areas but it is average value for $\mathrm{ZnO}$ film in literature [21-24]. This case may be the optical scattering mechanisms of film. So, the low transmittance value may be attributed to the high light scattering due to more rough surface properties according to literature. Also, the film has sharp absorption edge in the wavelength region between $360-380 \mathrm{~nm}$. The reflectance spectrum shows in Figure 4 (c). It was investigated that the average reflectance value of $\mathrm{ZnO}$ film is below $10 \%$ in the visible region of spectrum.

Also, we calculated the band gap value of $\mathrm{ZnO}$ film. The sharp step required for measuring the thickness in this method. So, we used the thickness value which determined by spectroscopic ellipsometry. This measured thickness value was used to calculate the absorption coefficient and band gap value of $\mathrm{ZnO}$ film. For this calculation, we used the optical method and the Tauc relationship [25] as follows:

$$
\alpha h v=A\left(h v-E_{g}\right)^{n}
$$

where $\alpha$ is the absorption coefficient, $A$ the constant, $h$ the Planck's constant, $n$ the photon frequency, $E_{g}$ the optical band gap, and $n$ the $1 / 2$ for direct band gap semiconductors. Since $E_{g}=h v$ when $(\alpha h v)^{2}=0$, an extrapolation of the linear region of the plot of $(\alpha h v)^{2}$ versus photon energy $(h v)$ on the x-axis gives the value of the optical band gap $E_{g}$. According to this calculation, we calculated the bad gap value as $3.21 \mathrm{eV}$ for the $\mathrm{ZnO}$ film and the $(\alpha h v)^{2}$ versus photon energy $(h v)$ graphic is shown in Figure 5. 


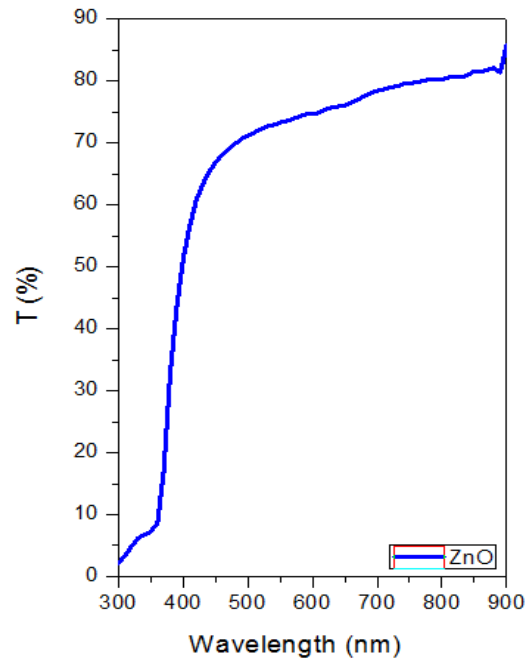

(a)

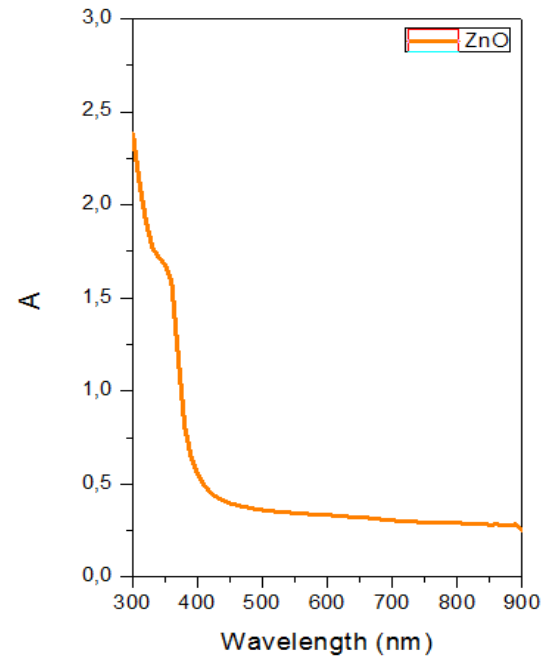

(b)

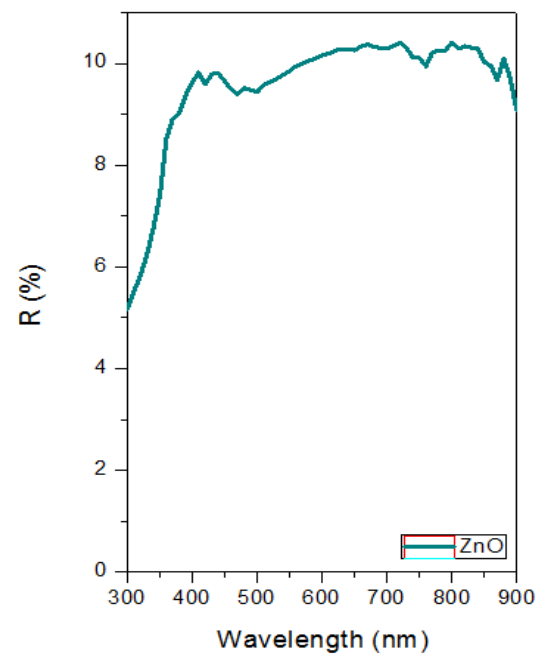

(c)

Figure 4. The optical (a) transmittance (T), (b) absorbance $(A)$ and (c) reflectance $(R)$ spectra

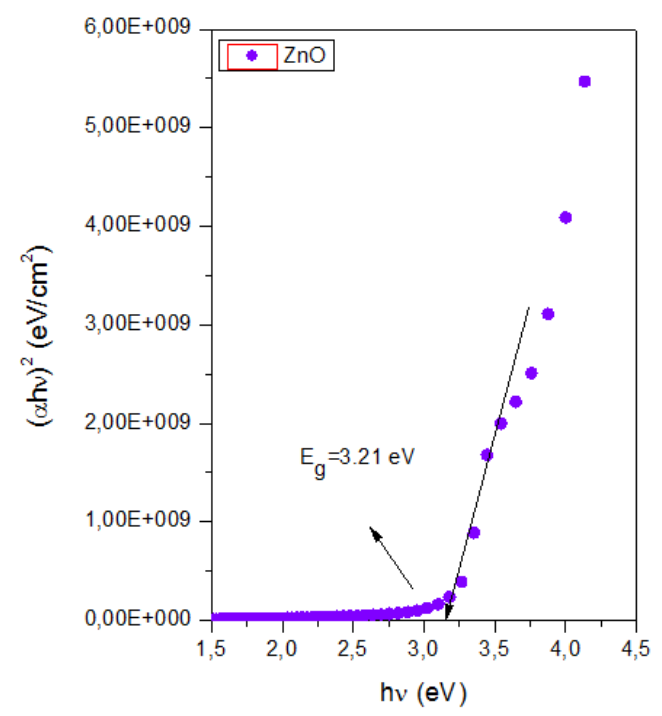

Figure 5. $(\alpha h v)^{2}$ versus photon energy $(h v)$ graphic of $\mathrm{ZnO}$ film 
The surface morphology, size and roughness value of produced $\mathrm{ZnO}$ film were analyzed by using the field emission scanning (FESEM) and atomic force microscopes (AFM). Figure 6 shows the respective FESEM image at different magnification ratio. It can be seen that the surface of $\mathrm{ZnO}$ film is generally dense, smooth, uniform and homogeneous. $\mathrm{ZnO}$ film has well-grown flower-like morphology, uniform size distribution and less aggregate. Flower-like structure of size is approximate $40 \mathrm{~nm}$ in width. Also, the some anisotropic column structure occurred due to the accumulated densely particle on the surface of film. We think that these areas have denser $\mathrm{Zn}^{+2}$ concentration and larger particles, because as it is known the alkaline solution type and amount as $\mathrm{NaOH}$ play significantly role crystalline and surface morphology during hydrothermal process. The similar results have been observed by Le et. al [26]. The AFM images of all films were taken from an area of $5 \times 5 \mu \mathrm{m}^{2}$ and the roughness values belong to all scanned area. These images are shown in Figure 7. As seen in Fig. 7, all the films look dense with a smoother surface and there are different regions on the film surface as deposited $\mathrm{ZnO}$ film with various heights. It is assumed that this smooth and flower structure may probably have positive effect on the optical and structural properties, as mentioned before. The $R_{p v}$ (peak-valley), $R_{q}$ (rms/root-mean-square) and $R_{a}$ (average roughness) values of the $\mathrm{ZnO}$ films are listed in Table 3.

The electrical resistivity values of $\mathrm{ZnO}$ films were recorded at room temperature. The four probe and hot probe technique were used to find the resistivity of the films. The electrical resistivity values were displayed in Table III. Also, the films were found to be n-type as determined from the hot probe.
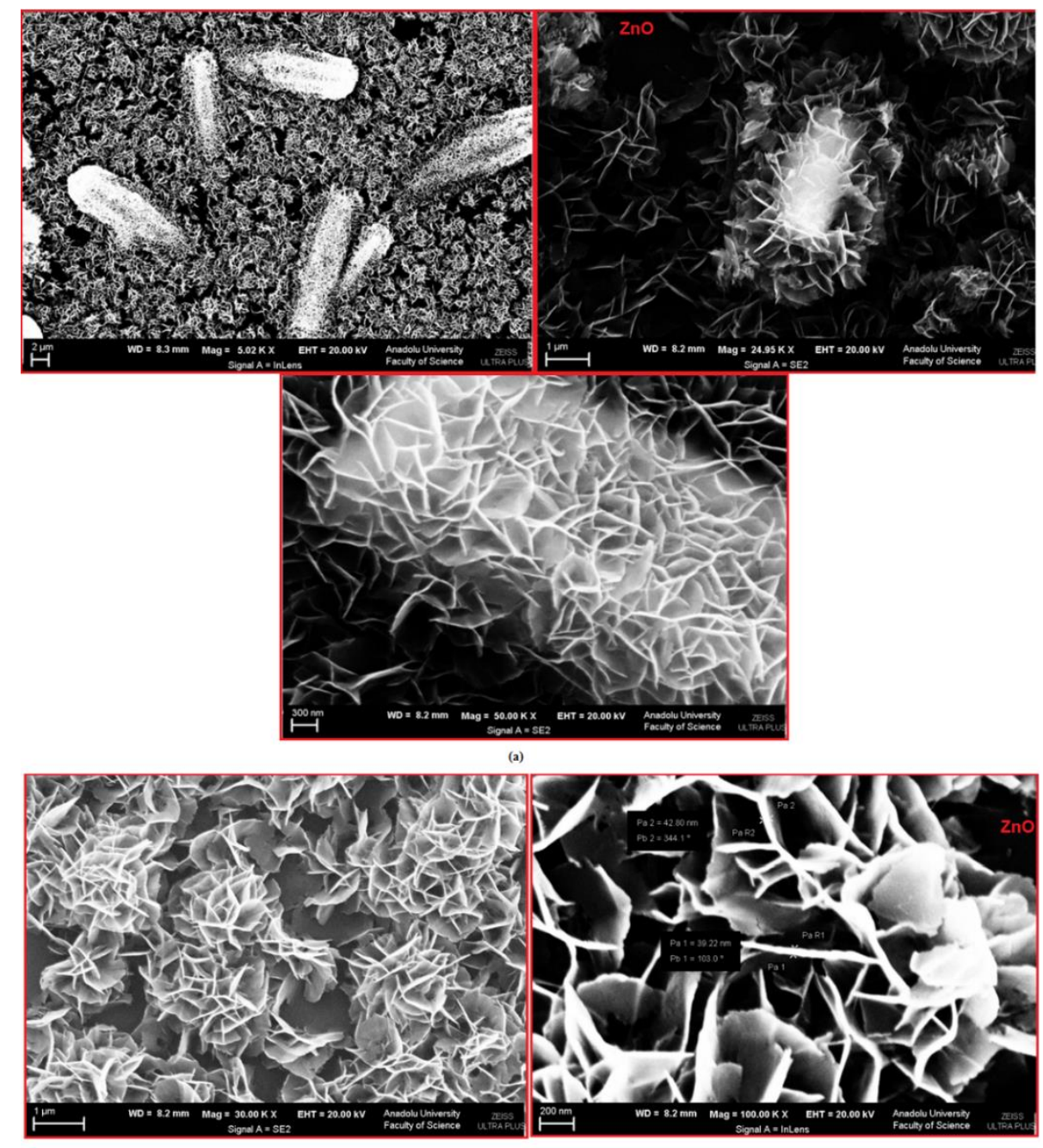

(b)

Figure 6. SEM images of $\mathrm{ZnO}$ films 

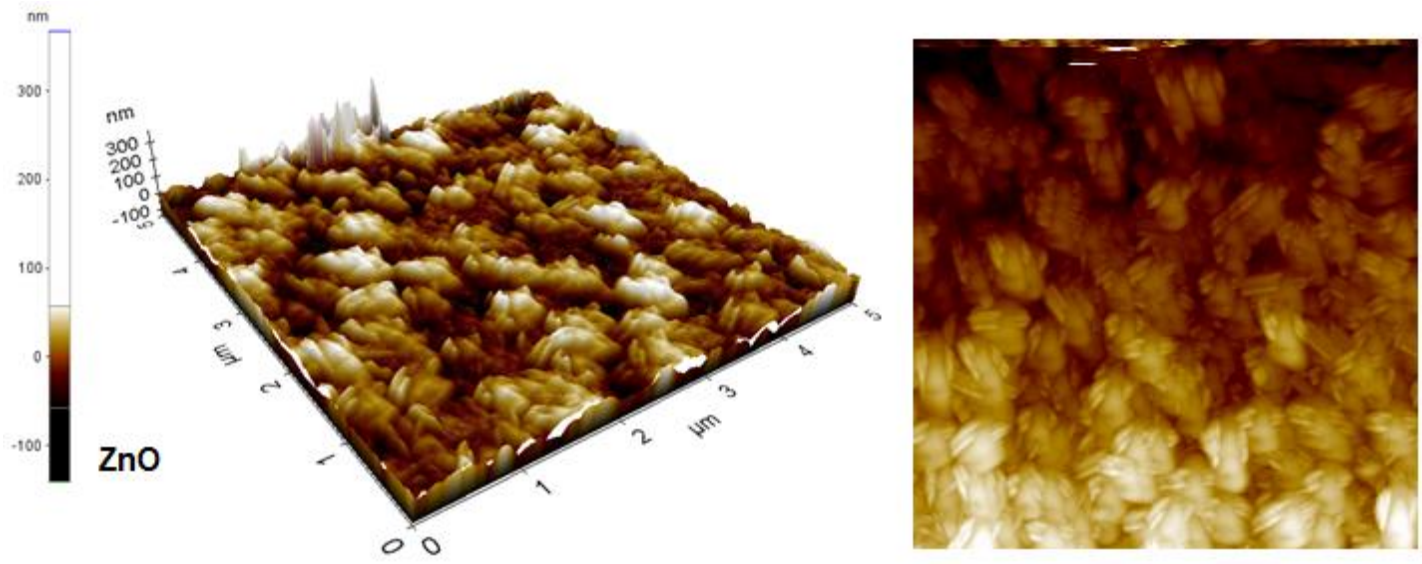

Figure 7. AFM images of $\mathrm{ZnO}$ films

Table 3. The roughness and electrical resistivity values of $\mathrm{ZnO}$ films

\begin{tabular}{|c|c|c|c|c|}
\hline Film & $\mathrm{R}_{\mathrm{a}}(\mathrm{nm})$ & $\mathrm{R}_{\mathrm{q}}(\mathrm{nm})$ & $\mathrm{R}_{\mathrm{pv}}(\mathrm{nm})$ & $\rho(\Omega . \mathrm{cm})$ \\
\hline $\mathrm{ZnO}$ & 23 & 29 & 508 & $1.02 \times 10^{-3}$ \\
\hline
\end{tabular}

\section{CONCLUSION}

In this study, $\mathrm{ZnO}$ films were successfully produced on glass substrates using hydrothermal synthesis at low temperature. The effects of on the structural, optical, surface and electrical properties of $\mathrm{ZnO}$ film, which are produced at low temperature, were studied. The results show that hydrothermal synthesis, which is the low cost of the production system, is an advantage for potential applications of $\mathrm{ZnO}$ films. The XRD results indicated that the higher quality crystalline structure according to other chemical synthesis techniques. The Cauchy-Urbach dispersion model was used for the determination of the thickness and optical constants of $\mathrm{ZnO}$ films. The refractive index value was investigated as 2.1. The band gap values calculated as $3.21 \mathrm{eV}$ using the optical method. Also, SEM and AFM images exhibited a flower-like morphology, homogeneous and low roughness values. We contained that $\mathrm{NaOH}$ solution, which was used in chemical solution, prominently affected in both the structure and surface properties of $\mathrm{ZnO}$ films. However, more research is needed to production parameter effects for various structure $\mathrm{ZnO}$ films and improving. The achieved results show that these $\mathrm{ZnO}$ films can effectively be used for many material researches and various application areas.

\section{ACKNOWLEDGMENTS}

Author is thankful to Prof. Dr. Ferhunde ATAY and Prof. Dr. İdris Akyüz, University of Eskisehir Osmangazi University, Eskişehir, Turkey, and Dr. Turan Taşköprü, University of Anadolu University, Eskişehir, Turkey, for providing the facilities of XRD, UV, AFM, SE and FESEM.

\section{REFERENCES}

[1] Kumar M, Kim T. H, Kim S. Lee B. T. Growth of epitaxial p-type ZnO thin films by codoping of Ga and N. Appl. Physics. Lett 2006; 89:112103. 
[2] Shivaraj B. W, Narasimha Murthy H. N, Krishna M, Satyanarayana B.S. Effect of Annealing Temperature on Structural and Optical properties of Dip and Spin coated ZnO Thin Films. Procedia Materials Science 2015; 10:292 - 300.

[3] Kenanakis G, Katsarakis N, Koudoumas E. Influence of precursor type, deposition time and doping concentration on the morphological, electrical and optical properties of $\mathrm{ZnO}$ and $\mathrm{ZnO}: \mathrm{Al}$ thin films grown by ultrasonic spray pyrolysis. Thin Solid Films 2014; 555:62-67.

[4] Urgessa Z. N, Oluwafemi O. S, Botha J. R. Hydrothermal synthesis of ZnO thin films and its electrical characterization. Material Letters 2012; 79:266-269.

[5] Taunk P. B, Das R, Bisen D. P, Tamrakar R. K, Rathor N. Synthesis and optical properties of chemical bath deposited $\mathrm{ZnO}$ thin film. International Journal of Modern Science 2015; 1 (3):159-165.

[6] Kaur G, Mitra A, Yadav K. L. Pulsed laser deposited Al-doped ZnO thin films for optical applications. Progress in Natural Science: Materials International 2015; 25:12-21.

[7] Choopun S, Tabata H, Kawai T. Self-assembly $\mathrm{ZnO}$ nanorods under argon atmosphere. J. Cryst. Growth 2005; 274:167-172.

[8] Vayssieres I, Keis K, Lindquist S, Hagfelt A. Three-Dimensional Array of Highly Oriented Crystalline ZnO Microtubes. J. Phys. Chem. B 2001; 105:3350.

[9] Yang L. L, Zhao Q. X, Willander M. J. Size- controlled growth of well-alliged ZnO nanrod arrays with two-step chemical bath deposition method. J. Alloys Compd 2009; 469:623-629.

[10] Jacobs K, Balitsky D, Armand P, Papet P. Low-temperature chemical bath deposition of crystalline ZnO. Solid State Sci. 2010; 12:333-338.

[11] Weintraub B, Zhou Z, Li Y, Deng Y. Solution synthesis of one-dimensional ZnO nanomaterials and their applications. Nanoscale 2010; 2:1573-1587.

[12] Zelalem N. U, Oluwatobi S. O, Johannes R. B. Hydrothermal synthesis of ZnO thin films and its electrical characterization. Material Letters 2012; 79:266-269.

[13] Sun Y, Ashfold M, Fuge M. Growth of aligned $\mathrm{ZnO}$ nanorod arrays by catalyst-free pulsed laser deposition methods. Chem. Phys. Lett 2004; 396:21-26.

[14] Rajkumar P. V, Ravichandran K, Baneto M, Ravidhas C, Sakthivel B, Dineshbabu N. Enhancement of optical and electrical properties of SILAR deposited $\mathrm{ZnO}$ thin films through fluorine doping and vacuum annealing for photovoltaic applications. Material Science and Semiconductor Processing 2015; 35:189-196.

[15] Muthukrishnan K, Vanaraja M, Boomadevi S, Karn R. K, Singh V, Singh P. K, Pandiyan K. Studies on acetone sensing characteristics of $\mathrm{ZnO}$ thin film prepared by sol-gel dip coating. Journal of Alloys and Compounds 2016; 673:138-143.

[16] Son N. T, Noh J. S, Park S. Role of $\mathrm{ZnO}$ thin film in the vertically aligned growth of $\mathrm{ZnO}$ nanrods by chemical bath deposition. Applied Surface Science 2016; 379:440-445.

[17] Suryanarayana C, Norton M. G, X-ray Diffraction-A Pratical Approroach, Plenum Press, New York and London (1998), p. 125.

[18] Romerdo R, Leinen D, Dalchiele E. A, Ramos-Barrado J. R, Martin F. The effects of zinc acetate and zinc chloride precursors on the preferred crystalline orientation of $\mathrm{ZnO}$ and $\mathrm{Al}$-doped $\mathrm{ZnO}$ thin films obtained by spray pyrolysis. Thin Solid Films 2006; 515:1942-1949. 
[19] Yang Y, Sun X.W, Chen B. J, Xu C. X, Chen T. P, Sun C. Q, Tay B. K, Sun Z. Refractive indices of textured indium tin oxide and zinc oxide thin films. Thin Solid Films 2006; 510 (1-2): 95101.

[20] Khoshman J, Kordesch E. M, Optical characterization of sputtered amorphous aluminum nitride thin films by spectroscopic ellipsometry. J. Non-Cryst Sol 2005; 351: 3334-40.

[21] Mortezaali A, Taheri O, Hosseini Z. S. Thickness effect of nanostructured $\mathrm{ZnO}$ thin films prepared by spray method on structural, morphological and optical properties. Microelectronic Engineering 2016; 151:19-23.

[22] Lmai F, Moubah R, Amiri A. El, Abid ., Soumahoro I, Hassanain N, Colis S, Schmerber G, Dinia A., Lassri H. Spin wave study and optical properties in Fe-doped $\mathrm{ZnO}$ thin films prepared by spray pyrolysis technique. Optical Material 2016; 57:28-33.

[23] Muchuweni E, Sathiaraj T. S, Nyakotyo H. Effect of gallium doping on the structural, optical and electrical properties of zinc oxide thin films prepared by spray pyrolysis. Ceramic International 2016; 42 (8):10066-10070.

[24] Mimouni R, Kamoun O, Yumak A, Mhamdi A, Boubaker K, P Petkova, Amlouk M. Effect of Mn content on structural, optical, opto-thermal and electrical properties of $\mathrm{ZnO}: \mathrm{Mn}$ sprayed thin films compounds. Journal of Alloys and Compounds 2015; 645:100-111.

[25] Chaabouni F, Abaab M, Rezig B, Effect of the substrate temperature on the properties of $\mathrm{ZnO}$ films grown by RF magnetron sputtering. Mater. Sci. Eng. B 2004; 109:236-40.

[26] Chua S. J, Le H. Q, Tay C. B, Loh K. P, Fitzgerald E. Vertically Aligned Single Crystalline ZnO Nanorods Grown by Hydrothermal Synthesis and Theoretical Model for Predicting the Rod Denstiy. MRS Proceding 2006; 957:0957-K07-10. 